\title{
Cadmium Exposure Decreases Fasting Blood Glucose Levels and Exacerbates Type-2 Diabetes in a Mouse Model
}

\section{Mengyang Li}

Soochow University Medical College

\section{Shuai Wang}

Soochow University Medical College

\section{Xiuxiu Liu}

Soochow University Medical College

\section{Zhijie Sheng}

Soochow University Medical College

\section{Bingyan Li}

Soochow University Medical College

Jiafu Li

Soochow University Medical College

Jie Zhang

Soochow University Medical College

\section{Zengli Zhang ( $\sim$ zhangzengli@suda.edu.cn )}

Soochow University https://orcid.org/0000-0002-0108-0263

\section{Research Article}

Keywords: Cadmium, Type 2 diabetes, Lactate accumulation, Inflammation, Fibrosis

Posted Date: October 28th, 2021

DOI: https://doi.org/10.21203/rs.3.rs-956445/v1

License: (c) (1) This work is licensed under a Creative Commons Attribution 4.0 International License. Read Full License

Version of Record: A version of this preprint was published at Endocrine on January 18th, 2022. See the published version at https://doi.org/10.1007/s12020-021-02974-w. 


\section{Abstract \\ Purpose}

Although the effects of cadmium (Cd) on the development of diabetes have been extensively investigated, the relationship between $\mathrm{Cd}$ exposure and the severity of established diabetes is unclear. Herein, we investigate the effects of long-term exposure to $\mathrm{Cd}$ in a streptozotocin-induced mouse model of type 2 diabetes and the underlying mechanism.

\section{Methods}

C57BL/6 Mice were divided into the following four groups: 1) control group; 2) Cd-exposed group; 3) diabetic group; 4) Cd-exposed diabetic group. Cd exposure was established by the administration of 155 ppm $\mathrm{CdCl}_{2}$ in drinking water. After 25 weeks of treatment, serum fasting glucose and insulin were measured. Meanwhile, the liver and pancreas specimens were sectioned and stained with Hematoxylin and eosin. Gluconeogenesis, glycolysis, lactate concentration and fibrosis in liver were evaluated.

\section{Results}

Clinical signs attributable to diabetes were more apparent in Cd-exposed diabetic mice. Interestingly, Cd exposure significantly decreased fasting blood glucose levels in diabetic group. We further demonstrated that the glycolysis related hepatic enzymes, pyruvate kinase M2 (PKM-2) and lactic dehydrogenase A (LDHA) were both increased, while the gluconeogenesis related hepatic enzymes, phosphoenolpyruvate-1 (PCK-1) and glucose-6-phosphatase (G6Pase) were both decreased in Cd exposed diabetic mice, indicating that $\mathrm{Cd}$ increased glycolysis and inhibited gluconeogenesis in diabetic model. Moreover, lactate accumulation was noted accompanied by the increased inflammation and fibrosis in the livers of diabetic mice following Cd exposure.

\section{Conclusions}

Cd exposure disturbed glucose metabolism and exacerbated diabetes, providing a biological relevance that DM patients are at greater risk when exposed to $\mathrm{Cd}$.

\section{Introduction}

Diabetes mellitus (DM) is a major contributor to morbidity, mortality, and disability, which represents a critical public health issue[1]. As other chronic diseases, DM is also genetic and environmentally-related [2]. Environmental pollutants, such as heavy metals, have been implicated as contributing to the pathogenesis of DM. Cadmium (Cd) is an environmental pollutant and has been associated with DM [3, 4]. Prior research in animal models identified a dysregulation of glucose metabolism, specifically, a 
relationship between $\mathrm{Cd}$ exposure and increased blood glucose levels $[5,6]$. As reported, Cd exposure induced hyperglycemia, altered oxidative status and led to pancreatic $\beta$-cell dysfunction [7-10]. Our research group also found that $\mathrm{Cd}$ decreased serum insulin concentrations and induced insulin resistance[11]. We further suggested that urinary Cd levels in humans were positively associated with DM [12]. In human, a cohort study suggested that individuals with high levels of urine Cd and plasma CRP (creactive protein) were at developing type-2 diabetes (T2DM) [13]. However, the underlying molecular and cellular mechanisms remains unclear to properly assess the actual relation between $\mathrm{Cd}$ exposure and DM.

Although the effects of $\mathrm{Cd}$ on the development of diabetes have been extensively investigated, the relationship between $\mathrm{Cd}$ exposure and the severity of established diabetes is unclear. Cd toxicity was identified as the cause of Itai-itai disease[14]. Currently, Cd continues to pose a significant threat to human health worldwide. Cd exists in the earth's crust and is widely distributed in the environment due to industrial and agricultural activities[15]. Apart from occupational exposure, drinking water, cigarette smoking, recharged nickel-cadmium batteries and such foods as cereals, vegetables, potatoes, and meat products are the major sources of human Cd exposure[16, 17]. Owing to the high level of Cd pollution and the increasing prevalence of DM in industrialized countries, the effects of $\mathrm{Cd}$ exposure on the severity of established DM need to be better understood.

In the present study, we analyzed the effects of Cd exposure on diabetes in a T2DM mouse model, and we included analyses to describe changes in key hepatic metabolic enzymes in these mice. Lactate, inflammation and fibrosis were also analyzed in mouse livers after $\mathrm{Cd}$ exposure. These endpoints were used to better understand the possible mechanisms for an increased risk of diabetic severity caused by $\mathrm{Cd}$ exposure. Based on the widespread distribution of $\mathrm{Cd}$ in the environment and the increasing prevalence of DM in industrialized countries, our research provided biological relevance that DM patients are at greater risk for disease progression when exposed to $\mathrm{Cd}$.

\section{Materials And Methods}

\section{Animal model and treatment}

Eight-week-old C57BL/6 male mice were purchased from the Experimental Animal Centre of Soochow University (Suzhou, China). All mice were housed five per cage in poly-carbonate cages and maintained under a natural light/dark cycle at $18-28^{\circ} \mathrm{C}$ and $40-60 \%$ humidity. After acclimatization to laboratory conditions for one week, the mice were fed by high fat diet (26.2\% protein, $26.3 \%$ carbohydrate and $34.9 \%$ fat; Biopike company, D12492). Eight weeks later, mice were administered streptozotocin (STZ; $100 \mathrm{mg} / \mathrm{kg}$ ) once by intraperitoneal injection. One week later, mice with fasting blood glucose levels were measured by an automatic glucometer (Roche, Switzerland, ACCU-SHEK) and $\geq 16.7 \mathrm{mmol} / \mathrm{L}$ were defined as T2DM mice. Mice were then subdivided into the following four groups: 1) non-diabetic mice (CON, n=10); 2) non-diabetic mice administered 155 ppm $\mathrm{CdCl}_{2}$ in the drinking water ( $\left.\mathrm{Cd}, \mathrm{n=10}\right) ; 3$ ) diabetic mice (DM, $n=15) ; 4)$ diabetic mice administered $155 \mathrm{ppm} \mathrm{CdCl}_{2}$ in the drinking water $(\mathrm{DM}+\mathrm{Cd}$, 
$\mathrm{n}=15)$. After 25 weeks of treatment, all mice were sacrificed by cervical dislocation. Blood samples were collected from the retroorbital plexus and allowed to clot at room temperature for $10 \mathrm{~min}$ and then centrifuged at $3000 \times \mathrm{g}$ at $4^{\circ} \mathrm{C}$ for $10 \mathrm{~min}$ to obtain serum. Tissues were removed and fixed in $10 \%$ buffered formalin or frozen at $-80^{\circ} \mathrm{C}$. The study protocol was approved by the Soochow University Institutional Animal Care and Use Committee (SCKK2017-0006). All procedures were conducted in accordance with the guidelines of the care of laboratory animals[18].

\section{H\&E staining}

Liver and pancreas specimens from all experimental groups were fixed in $4 \%$ neutral buffered formalin, dehydrated, and embedded in paraffin. Pancreas were sectioned (5- $\mu \mathrm{m}$ thickness) and stained with hematoxylin and eosin (H\&E, Beyotime, China). Histological features were observed using light microscopy (CKX41, OLYMPUS, Tokyo, Japan).

\section{Masson trichrome collagen staining}

The liver sections were stained with Weigert's iron hematoxylin solution for $5 \mathrm{~min}$, acid ethanol for $10 \mathrm{~s}$ and then washed with tap water. Sections were counterstained with Masson trichrome stain (Sbjbio, China) for $4 \mathrm{~min}$, then washed with tap water for $1 \mathrm{~min}$. Sections were then stained with Ponceau stain for 5 min and washed with phosphomolybdic acid for 2 min. Next, a weak acid working solution (pH 5.8) was used to wash the sections for $1 \mathrm{~min}$. Sections were then stained with aniline blue for $2 \mathrm{~min}$ and washed with the weak acid working solution for 1 min. Finally, sections were washed with $95 \%$ and $100 \%$ ethyl alcohol three times for $10 \mathrm{~s}$ and xylene for $1 \mathrm{~min}$ each.

\section{Enzyme-linked immunosorbent (ELISA) assay}

The level of insulin in serum was measured by ELISA (Elabscience Biotechnology, Wuhan, China) according to the manufacturer's instructions. Optical density (OD) was measured at $450 \mathrm{~nm}$. Insulin concentrations were expressed as $\mathrm{pg} / \mathrm{ml}$.

\section{Lactate assay}

Tissues lactate concentrations were determined using the Lactate Assay Kit (Nanjing Jiancheng Bioengineering Institute, Nanjing, China). The tissues were homogenized with a grinding miller and the supernatants were extracted and centrifuged $(10000 \mathrm{~g}, 10 \mathrm{~min})$. The solutions from the assay kit were mixed and incubated for $10 \mathrm{~min}$ at $37^{\circ} \mathrm{C}$, and the reaction was stopped by stop solution. The OD was measured at $530 \mathrm{~nm}$. The concentrations of lactate in tissue were normalized and expressed as $\mathrm{mmol} / \mathrm{g}$ protein, serum lactate levels were expressed as $\mathrm{mmol} / \mathrm{L}$.

\section{Western blot}

Tissues were lysed in RIPA lysis buffer (Beyotime, Shanghai, China) with protease inhibitors. Protein concentrations were determined using a BCA protein assay kit (Beyotime). Equal amounts of sample 
were separated on SDS-PAGE and transferred to PVDF membranes. The samples were blocked with $5 \%$ skimmed milk in PBS-T, and then incubated with antibodies for PKM-2, lactate dehydrogenase-A (LDHA), and GAPDH as a loading control (all rabbit monoclonal antibodies, diluted 1:1000). Blots were incubated with goat antirabbit IgG secondary antibody (diluted 1:3000). Reactive signals were detected by a chemiluminescence imager (Gene GnomeXRQ, Gene Company Limited).

\section{Quantitative Real-Time PCR}

Total RNA was extracted from tissue using the Total RNA Extraction Kit (Invitrogen, USA). Extracted RNA was used as a template for reverse transcription using the RT Reagent Kit. Real-time quantitative PCR was performed using the ABI 7300 Real-time PCR System and SYBR Premix Ex Taq ${ }^{\mathrm{TM}}$ II. The reaction was performed in a final volume of $20 \mu \mathrm{L}$. The cycle began with an initial denaturing step for $1 \mathrm{~min}$ at $95^{\circ} \mathrm{C}$ followed by 40 PCR cycles: $15 \mathrm{~s}$ at $95^{\circ} \mathrm{C}$ and $25 \mathrm{~s}$ at $63^{\circ} \mathrm{C}$. Relative gene expression was calculated using the 2- $\Delta \Delta \mathrm{Ct}$ method. The sequences of the forward $(\mathrm{F})$ and reverse $(\mathrm{R})$ primers are presented at Table 1.

\section{Statistical analysis}

All quantitative data are expressed as the mean \pm SD of independent experiments. Comparisons between two groups were analyzed using Student's $t$-test, and comparisons between more than two groups were made using one-way ANOVA to identify differences among means. A value of $P<0.05$ was considered statistically significant. Statistical analyses were performed and graphs were created, using a GraphPad cameyo statistical package.

\section{Results}

\section{Cd exacerbated clinical signs in diabetic mice}

Cd mice showed no sign of Cd toxicity, whose body weight were similar as control mice. Both DM mice and $\mathrm{Cd}+\mathrm{DM}$ mice showed diabetic signs including polyuria, polydipsia, and polyphagia, whose body weight significantly decreased compared with the control mice (Fig. 1A). Moreover, the body weight of the $\mathrm{DM}+\mathrm{Cd}$ mice was significantly less than the DM mice (Fig. 1B). In the later period of experiment, significantly decreased locomotor activity were found in DM and Cd+DM group mice, especially in $\mathrm{Cd}+\mathrm{DM}$ group mice. Six mice died during experiment period in $\mathrm{DM}+\mathrm{Cd}$ group and no death was found in other three groups.

\section{Cd decreased fasting blood glucose and serum insulin levels in diabetic mice}

There was no significant difference in fasting blood glucose (FBG) levels between $\mathrm{Cd}$ and CON mice. The DM mice were hyperglycemic compared with the CON mice, but Cd treatment decreased the FBG in DM mice compared with the DM mice without exposure to Cd. (Fig. 1C). The fasting serum insulin levels in the DM+Cd mice were also decreased compared with DM mice (Figure 1D), and this finding was 
supported histopathologically by the abnormal shapes of islets in the diabetic mice after $\mathrm{Cd}$ treatment (Figure 1E).

\section{Cd enhanced glycolysis and inhibited gluconeogenesis in diabetic mice}

Results from western blot for hepatic PKM-2 and LDHA showed significant increases in DM+Cd mice compared with CON mice; however, the protein levels of PKM-2 and LDHA in DM+Cd mice were not statistically different from those of the DM mice, (Figure 2A). These findings nevertheless suggested Cd exposure may increase glycolysis in diabetic mice. In contrast (Figure 2B), the relative mRNA levels of $P C K-1$ and G6Pase in the livers of $\mathrm{DM}+\mathrm{Cd}$ mice were significantly decreased compared with the other three groups. These data indicated that $\mathrm{Cd}$ inhibited gluconeogenesis in diabetic mice.

\section{Cd promotes liver lactate accumulation in diabetic mice}

Lactate is an end-product of glycolysis. As shown in Figure 3, the concentrations of hepatic lactate in $\mathrm{DM}+\mathrm{Cd}$ mice were much higher than other three groups. These data indicated that $\mathrm{Cd}$ enhanced the accumulation of hepatic lactate in diabetic mice.

\section{Cd promoted inflammation in diabetic mice}

After diabetic mice were treated with Cd, relative mRNA levels of inflammatory biomarkers interleukin-6 $(I L-6)$ in livers of $D M+C d$ group were increased compared with the other three groups. Furthermore, transforming growth factor- $\beta$ (TGF- $\beta$ ) was increased in livers of $D M+C d$ group compared with the CON and Cd groups (Figure 3B).

\section{Cd promoted fibrosis in diabetic mice}

Cd significantly increased the mRNA levels of Collagen I in diabetic mouse livers compared with other three groups, and Cd significantly increased hepatic Collagen III levels in these mice compared with CON and $\mathrm{Cd}$ mice (Figure 4A). Masson trichrome collagen staining showed that $\mathrm{DM}+\mathrm{Cd}$ mice had the greatest amount of fibrosis compared to other three groups (Fig. 4B).

\section{Discussion}

In this study, we observed that Cd exacerbated the clinical signs and progression of diabetes in the T2DM mice. High fat diet combined with administration of STZ is frequently used to produce experimental type 2 diabetes mellitus. In the present study, STZ-induced mice are characterized by a significant hyperglycemia, loss of body weight, polyphagia and polydipsia, which is classic diabetic symptoms. Cd exposure decreased body weight, serum insulin level and locomotor activity in diabetic mice. The phenomenon is consistent with the clinical picture of advanced diabetes in humans, which is characterized by decreased serum insulin content, physical weakness and high mortality [16]. The results provides a biological relevance that DM patients are at greater risk when exposed to $\mathrm{Cd}$. 
Surprisingly, Cd decreased the FBG levels in diabetic mice despite the serum insulin concentrations being decreased. This is in contrast with some published studies where $\mathrm{Cd}$ was reported to increase FBG levels in normal mice or diabetic mice $[20,21]$. However, our data were consistent with other studies showing that $\mathrm{Cd}$ decreased FBG levels $[22,23]$. The reasons for this discrepancy, and the anomaly of FBG and insulin both decreasing, are unclear. A full resolution to this apparent discrepancy will be the focus of future research.

Liver plays a key role in blood glucose regulation by glycolysis and gluconeogenesis. To determine whether $\mathrm{Cd}$ exposure existed effects on glycolysis and gluconeogenesis, contents of several enzymes in liver were investigated. The PKM enzyme is a rate-controlling key glycolytic enzyme in glycolysis, which catalyzes the conversion of phosphoenolpyruvate to pyruvate [24]. LDHA is one of the endpoint of glycolysis pathway, catalyzing the formation of lactate from pyruvate [25]. We found that Cd significantly stimulated the expression of PKM-2 and LDHA in the liver of diabetic mice, which indicates Cd increased liver glycolysis in diabetic mice. Studies reported that $\mathrm{Cd}$ stimulated liver glycolysis in aquatic organism. However, there is no report about the effect of Cd exposure on liver glycolysis in mammals. Published studies suggested that Cd promoted glycolysis in lung and neuronal cells in rats [26, 27]. In the present study, increased lactate production in liver of Cd-exposed mice supported the idea that $\mathrm{Cd}$ increased glycolysis.

PEPCK is a key enzyme of gluconeogenesis in the liver $[28,29]$. We found no significant difference in expression of PCK-1 between diabetic mice and control mice. However, Cd exposure significantly decreased the expression of PCK-1 in diabetic mice liver. PEPCK is a rate-limiting step in gluconeogenesis, which catalyzes the conversion of oxaloacetate to phosphoenolpyruvate. So, activity of PEPCK determines the amount of glucose produced. Thus, the decreased expression of PCK-1 indicates $\mathrm{Cd}$ decreased gluconeogenesis in diabetic mice. Besides, G6Pase is an another essential enzyme to gluconeogenesis, which induce the hydrolysis from glucose-6-phosphate to glucose[30]. In this study, the mRNA levels of both PCK-1 and G6Pase were inhibited by Cd exposure, which indicated that Cd inhibited hepatic gluconeogenesis in diabetic mice.

Based on these results, it can be concluded that the marked decrease in blood glucose level in Cd exposed mice, as observed in the present study, may result from promoted glucose metabolism by glycolysis and inhibiting hepatic endogenous glucose production by gluconeogenesis.

It is paradoxical that improved glucoregulation and exacerbated diabetic symptoms. Next, lactate concentration was studied. As expected, significant increased lactate production was found in the liver of diabetic mice after $\mathrm{Cd}$ exposure, which may result from decreased gluconeogenesis and increased glycolysis. Lactate, the end product of glycolysis, is acknowledged as an energy source and intermediary metabolic product[31]. Excessive lactate production results in lactic acidosis, which is a rare but lifethreatening complication of DM[32]. However, it is not clear the side effects of elevated lactate concentration which is below the lactic acidosis level. Researches focus on the metabolic flexibility of lactate in disease. However, little is known about the underlying mechanism of the non-metabolic 
functions and accumulation of lactate in pathological progression. Healthy liver exhibits higher lactate clearance than any other organ[33]. A report found that blood lactate might be an independent risk factor for the development of type 2 diabetes. A prospective study reported that blood lactate predicted incident diabetes independent of many other risk factors and was strongly related to insulin resistance. In human, lactate accumulation was found in chronic liver disease [34]. Published studies reported that increased liver lactate levels stimulated hepatic stellate cells activation and contributed to the severity of fibrosis. It was reported that lactate augmented LPS-stimulated inflammatory gene expression. Non-alcoholic fatty liver disease is a common complication of DM with incidence rate $50 \%[35]$. Therefore, the mice liver fibrosis was investigate in the present study. We found that $\mathrm{Cd}$ exposure indeed worsen liver fibrosis in diabetic mice. Consistent with the effects of $\mathrm{Cd}$ on fibrosis, we also found that $\mathrm{Cd}$ increased the expression of IL-6, TGF- $\beta$, Collagen I and Collagen III in diabetic mice liver. These cytokines may involve in the process of worsen fibrosis induced by $\mathrm{Cd}$. Besides, published studies had shown that hepatic lactate was related to inflammatory stress [36], which is consistent with this study. In general, Cd increased the lactate concentrations and promoted liver inflammation in diabetic mice liver, and increased inflammatory stress is the possible reason resulted in liver fibrosis. Together, our data support several possible mechanisms for the exacerbated clinical signs associated with $\mathrm{Cd}$ exposure in T2DM mice.

The results of our study have potentially broad biological relevance. The numbers of people who live in Cd contaminated areas or who are exposed to $\mathrm{Cd}$ in the workplace and those who are diagnosed with DM has increased rapidly worldwide [37-41]. Greater insight into the interaction of Cd and DM is essential. However, there were some limitations of this study. Specifically, we did not further explore those mechanisms related to the changes reported for blood glucose and insulin. These would be the focus of future research.

\section{Conclusion}

In a T2DM mouse model, $\mathrm{Cd}$ exposure disturbed glucose metabolism and exacerbated diabetes. Increased hepatic lactate accumulation, inflammation and fibrosis may contribute to the effects of $\mathrm{Cd}$. The data support the hypothesis that $\mathrm{Cd}$ exposure is a risk factor for the exacerbation of diabetes.

\section{Declarations}

\section{Funding}

This research was supported by the National Natural Scientific Funding of China (No.81773414, No.81673151) and this is a project funded by Priority Academic Program Development of Jiangsu Higher Education Institutions (PAPD).

\section{Author Contributions}

Mengyang Li, Shuai Wang and Zengli Zhang conceived and designed the experiments; Mengyang Li, and Shuai Wang performed the experiments; Bingyan Li, Shuai Wang, Xiuxiu Liu and Zhijie Sheng contributed 
reagents/materials/analysis tools; Jie Zhang, Mengyang Li, Xiuxiu Liu and Jiafu Li analyzed the data; Mengyang Li and Zengli Zhang wrote the paper.

\section{Declaration of Competing Interest}

The authors declare that they have no conflicts of interest.

\section{References}

1. K. Kaul, J.M. Tarr, S.I. Ahmad, E.M. Kohner, R. Chibber, Introduction to diabetes mellitus. Advances in experimental medicine and biology.771(2012)1-11.http://www.ncbi.nlm.nih.gov/pubmed/23393665

2. A. Katsarou, S. Gudbjornsdottir, A. Rawshani, D. Dabelea, E. Bonifacio, B.J. Anderson et al., Type 1 diabetes mellitus. Nature reviews Disease primers. Mar 30, 17016 (2017). http://www.ncbi.nlm.nih.gov/pubmed/28358037 3 ).

3. A.A. Tinkov, T. Filippini, O.P. Ajsuvakova, J. Aaseth, Y.G. Gluhcheva, J.M. Ivanova et al., The role of cadmium in obesity and diabetes. The Science of the total environment. Dec 1;601-602(2017)741-55. http://www.ncbi.nlm.nih.gov/pubmed/28577409

4. W. Liu, B. Zhang, Z. Huang, X. Pan, X. Chen, C. Hu et al. Cadmium Body Burden and Gestational Diabetes Mellitus: A Prospective Study. Environmental health perspectives. Feb 8;126(2018)027006. http://www.ncbi.nlm.nih.gov/pubmed/29425094

5. N. Kandasamy, N. Ashokkumar. Protective effect of bioflavonoid myricetin enhances carbohydrate metabolic enzymes and insulin signaling molecules in streptozotocin-cadmium induced diabetic nephrotoxic rats. Toxicology and applied pharmacology. Sep 1;279(2014)173-85. http://www.ncbi.nlm.nih.gov/pubmed/24923654

6. T. Senthilkumar, N. Sangeetha, N. Ashokkumar, Antihyperglycemic, antihyperlipidemic, and renoprotective effects of Chlorella pyrenoidosa in diabetic rats exposed to cadmium. Toxicology mechanisms and methods. Oct 22, 617-624 (2012). http://www.ncbi.nlm.nih.gov/pubmed/22827700

7. R. Fitzgerald, A. Olsen, J. Nguyen, W. Wong, M. El Muayed, J. Edwards. Pancreatic Islets Accumulate Cadmium in a Rodent Model of Cadmium-Induced Hyperglycemia. International journal of molecular sciences. Dec 31;22(2020).http://www.ncbi.nlm.nih.gov/pubmed/33396420

8. C. Zhang, T. Lin, G. Nie, R. Hu, S. Pi, Z. Wei et al. Cadmium and molybdenum co-induce pyroptosis via ROS/PTEN/PI3K/AKT axis in duck renal tubular epithelial cells. Environmental pollution. Mar 1;272(2021)116403.http://www.ncbi.nlm.nih.gov/pubmed/33433347

9. Y. Wang, A.K. Mandal, Y.O. Son, P. Pratheeshkumar, J.T.F. Wise, L. Wang et al. Roles of ROS, Nrf2, and autophagy in cadmium-carcinogenesis and its prevention by sulforaphane. Toxicology and applied pharmacology. Aug 15;353(2018)23-30.http://www.ncbi.nlm.nih.gov/pubmed/29885333

10. C.C. Huang, C.Y. Kuo, C.Y. Yang, J.M. Liu, R.J. Hsu, K.I. Lee et al. Cadmium exposure induces pancreatic beta-cell death via a $\mathrm{Ca}(2+)$-triggered JNK/CHOP-related apoptotic signaling pathway. 
Toxicology. Sep 1;425(2019)152252.http://www.ncbi.nlm.nih.gov/pubmed/31348969

11. X. Li, M. Li, J. Xu, X. Zhang, W. Xiao, Z. Zhang. Decreased Insulin Secretion but Unchanged Glucose Homeostasis in Cadmium-Exposed Male C57BL/6 Mice. Journal of toxicology. 2019(2019)8121834.http://www.ncbi.nlm.nih.gov/pubmed/31320898

12. F.F. Guo, Z.Y. Hu, B.Y. Li, L.Q. Qin, C. Fu, H. Yu et al., Evaluation of the association between urinary cadmium levels below threshold limits and the risk of diabetes mellitus: a dose-response metaanalysis. Environmental science and pollution research international. Jul 26, 19272-19281 (2019). http://www.ncbi.nlm.nih.gov/pubmed/31069655

13. L. Xiao, Y. Zhou, J. Ma, L. Cao, C. Zhu, W. Li et al., Roles of C-reactive protein on the association between urinary cadmium and type 2 diabetes. Environmental pollution Dec;255, 113341 (2019). http://www.ncbi.nlm.nih.gov/pubmed/31610512

14. R.A. Bernhoft. Cadmium toxicity and treatment. The Scientific World Journal. 2013(2013)394652. http://www.ncbi.nlm.nih.gov/pubmed/23844395

15. P.B. Tchounwou, C.G. Yedjou, A.K. Patlolla, D.J. Sutton, Heavy metal toxicity and the environment. Experientia supplementum 101, 133-164 (2012). http://www.ncbi.nlm.nih.gov/pubmed/22945569

16. G. Genchi, M.S. Sinicropi, G. Lauria, A. Carocci, A. Catalano. The Effects of Cadmium Toxicity. International journal of environmental research and public health. May 26;17(2020). http://www.ncbi.nlm.nih.gov/pubmed/32466586

17. S. Satarug, S.H. Garrett, M.A. Sens, D.A. Sens, Cadmium, environmental exposure, and health outcomes. Environmental health perspectives Feb;118, 182-190 (2010). http://www.ncbi.nlm.nih.gov/pubmed/20123617

18. J.D. Clark, G.F. Gebhart, J.C. Gonder, M.E. Keeling, D.F. Kohn. Special Report: The 1996 Guide for the Care and Use of Laboratory Animals. ILAR journal.38(1997)41-8.

http://www.ncbi.nlm.nih.gov/pubmed/11528046

19. S.L. Wu, Staging of type 2 diabetes mellitus. Genetics and molecular research: GMR. Mar 20;14(2015)2118-21.http://www.ncbi.nlm.nih.gov/pubmed/25867358

20. M. Kanter, M. Yoruk, A. Koc, I. Meral, T. Karaca, Effects of cadmium exposure on morphological aspects of pancreas, weights of fetus and placenta in streptozotocin-induced diabetic pregnant rats. Biol. Trace Elem. Res. Summer,93, 189-200 (2003). http://www.ncbi.nlm.nih.gov/pubmed/12835501

21. T. Jin, B.J. Frankel, Cadmium-metallothionein nephrotoxicity is increased in genetically diabetic as compared with normal Chinese hamsters. Pharmacology \& toxicology Sep;79, 105-108 (1996). http://www.ncbi.nlm.nih.gov/pubmed/8884866

22. P.K. Singh, D. Baxi, R. Diwedi, A.V. Ramachandran, Prior cadmium exposure improves glucoregulation in diabetic rats but exacerbates effects on metabolic dysregulation, oxidative stress, and hepatic and renal toxicity. Drug and chemical toxicology. Apr 35, 167-177 (2012). http://www.ncbi.nlm.nih.gov/pubmed/22268556 
23. O.I. Oluranti, E.A. Agboola, N.E. Fubara, M.O. Ajayi, O.S. Michael, Cadmium exposure induces cardiac glucometabolic dysregulation and lipid accumulation independent of pyruvate dehydrogenase activity. Annals of medicine Dec;53, 1108-1117 (2021). http://www.ncbi.nlm.nih.gov/pubmed/34259114

24. W. Qi, H.A. Keenan, Q. Li, A. Ishikado, A. Kannt, T. Sadowski et al., Pyruvate kinase M2 activation may protect against the progression of diabetic glomerular pathology and mitochondrial dysfunction. Nature medicine Jun;23, 753-762 (2017). http://www.ncbi.nlm.nih.gov/pubmed/28436957

25. S. Datta, N. Chakrabarti, Age related rise in lactate and its correlation with lactate dehydrogenase $(\mathrm{LDH})$ status in post-mitochondrial fractions isolated from different regions of brain in mice. Neurochem. Int. Sep;118, 23-33 (2018). http://www.ncbi.nlm.nih.gov/pubmed/29678731

26. X. Wang, Z. Li, Z. Gao, Q. Li, L. Jiang, C. Geng et al., Cadmium induces cell growth in A549 and HELF cells via autophagy-dependent glycolysis. Toxicology in vitro: an international journal published in association with BIBRA. Aug 66, 104834 (2020). http://www.ncbi.nlm.nih.gov/pubmed/32200033

27. F. Bovio, P. Melchioretto, M. Forcella, P. Fusi, C. Urani, Cadmium promotes glycolysis upregulation and glutamine dependency in human neuronal cells. Neurochemistry international. Jul 23, 105144 (2021). http://www.ncbi.nlm.nih.gov/pubmed/34303722 149).

28. T. Suhara, T. Hishiki, M. Kasahara, N. Hayakawa, T. Oyaizu, T. Nakanishi et al., Inhibition of the oxygen sensor PHD2 in the liver improves survival in lactic acidosis by activating the Cori cycle. Proceedings of the National Academy of Sciences of the United States of America. Sep 15, 1164211647 (2015). http://www.ncbi.nlm.nih.gov/pubmed/26324945 112 ).

29. H. Yan, W. Yang, F. Zhou, X. Li, Q. Pan, Z. Shen et al., Estrogen Improves Insulin Sensitivity and Suppresses Gluconeogenesis via the Transcription Factor Foxo1. Diabetes. Feb;68(2019)291-304. http://www.ncbi.nlm.nih.gov/pubmed/30487265

30. J. Goncalves, Y. Wan, X. Guo, K. Rha, B. LeBoeuf, L. Zhang et al. Succinate Dehydrogenase-Regulated Phosphoenolpyruvate Carboxykinase Sustains Copulation Fitness in Aging C. elegans Males. iScience. Apr 24;23(2020)100990.http://www.ncbi.nlm.nih.gov/pubmed/32240955

31. R.A. Robergs, C.R. McNulty, G.M. Minett, J. Holland, G. Trajano. Lactate, not Lactic Acid, is Produced by Cellular Cytosolic Energy Catabolism. Physiology. Jan 1;33(2018)10-2. http://www.ncbi.nlm.nih.gov/pubmed/29212886

32. J. Seheult, G. Fitzpatrick, G. Boran. Lactic acidosis: an update. Clinical chemistry and laboratory medicine. Mar 1;55(2017)322-33.http://www.ncbi.nlm.nih.gov/pubmed/27522622

33. H. Possemiers, L. Vandermosten, P.E. Van den Steen, Etiology of lactic acidosis in malaria. PLoS pathogens. Jan 17, e1009122 (2021). http://www.ncbi.nlm.nih.gov/pubmed/33411818

34. T. Wang, K. Chen, W. Yao, R. Zheng, Q. He, J. Xia et al., Acetylation of lactate dehydrogenase B drives NAFLD progression by impairing lactate clearance. Journal of hepatology. May 74, 1038-1052 (2021). http://www.ncbi.nlm.nih.gov/pubmed/33248168

35. P. Burra, C. Becchetti, G. Germani, NAFLD and liver transplantation: Disease burden, current management and future challenges. JHEP reports: innovation in hepatology. 
Dec;2(2020)100192.http://www.ncbi.nlm.nih.gov/pubmed/33163950

36. T. Wang, W. Yao, J. Li, Q. He, Y. Shao, F. Huang. Acetyl-CoA from inflammation-induced fatty acids oxidation promotes hepatic malate-aspartate shuttle activity and glycolysis. American journal of physiology Endocrinology and metabolism. Oct 1;315(2018)E496-E510.

http://www.ncbi.nlm.nih.gov/pubmed/29763372

37. Y.J. Liao, C.X. Xu, C.Q. Ma, Z.W. Qin, Y.J. Su, H.R. Zhu et al., [Effect of occupational factors on prediabetes mellitus among iron and steel workers]. Zhonghua liu xing bing xue za zhi = Zhonghua liuxingbingxue zazhi. Jun 10, 929-933 (2020). http://www.ncbi.nlm.nih.gov/pubmed/32564562 41(

38. A.M. Yang, N. Cheng, H.Q. Pu, S.M. Liu, J.S. Li, B.A. Bassig et al., Metal Exposure and Risk of Diabetes and Prediabetes among Chinese Occupational Workers. Biomedical and environmental sciences: BES. Dec;28(2015)875-83.http://www.ncbi.nlm.nih.gov/pubmed/26777907

39. M. Bennasar-Veny, S. Fresneda, A. Lopez-Gonzalez, C. Busquets-Cortes, A. Aguilo, A.M. Yanez. Lifestyle and Progression to Type 2 Diabetes in a Cohort of Workers with Prediabetes. Nutrients. May 25;12(2020).http://www.ncbi.nlm.nih.gov/pubmed/32466178

40. L. Kozlowska, J. Gromadzinska, W. Wasowicz, Health risk in transport workers. Part II. Dietary compounds as modulators of occupational exposure to chemicals. International journal of occupational medicine and environmental health. Jul 15, 441-464 (2019). http://www.ncbi.nlm.nih.gov/pubmed/31099343 32 ).

41. S. Baloch, T.G. Kazi, J.A. Baig, H.I. Afridi, M.B. Arain. Occupational exposure of lead and cadmium on adolescent and adult workers of battery recycling and welding workshops: Adverse impact on health. The Science of the total environment. Jun 10;720(2020)137549.

http://www.ncbi.nlm.nih.gov/pubmed/32135282

\section{Tables}

Table1. Real-time PCR primer sequences.

\begin{tabular}{|lll|}
\hline Gene Name & Forward Sequence $\left(\mathbf{5}^{\prime} \mathbf{3}^{\prime} \mathbf{)}\right.$ & Reverse Sequence $\left(\mathbf{5}^{\prime} \mathbf{3}^{\prime} \mathbf{)}\right.$ \\
\hline PCK-1 & AGCATTCAACGCCAGGTTC & CGAGTCTGTCAGTTCAATACCAA \\
\hline G6Pase & CGACTCGCTATCTCCAAGTGA & GGGCGTTGTCCAAACAGAAT \\
\hline IL-6 & GAGGATACCACTCCCAACAGACC & AAGTGCATCATCGTTGTTCATACA \\
\hline TGF- $\beta$ & ATCCTGTCCAAACTAAGGCTCG & ACCTCTTTAGCATAGTAGTCCGC \\
\hline Collagen I & AGGCTTCAGTGGTTTGGATG & CACCAACAGCACCATCGTTA \\
\hline Collagen III & AAGGCTGCAAGATGGATGCT & GTGCTTACGTGGGACAGTCA \\
\hline GAPDH & ACTCCACTCACGGCAAATTC & TCTCCATGGTGGTGAAGACA \\
\hline
\end{tabular}




\section{Figures}

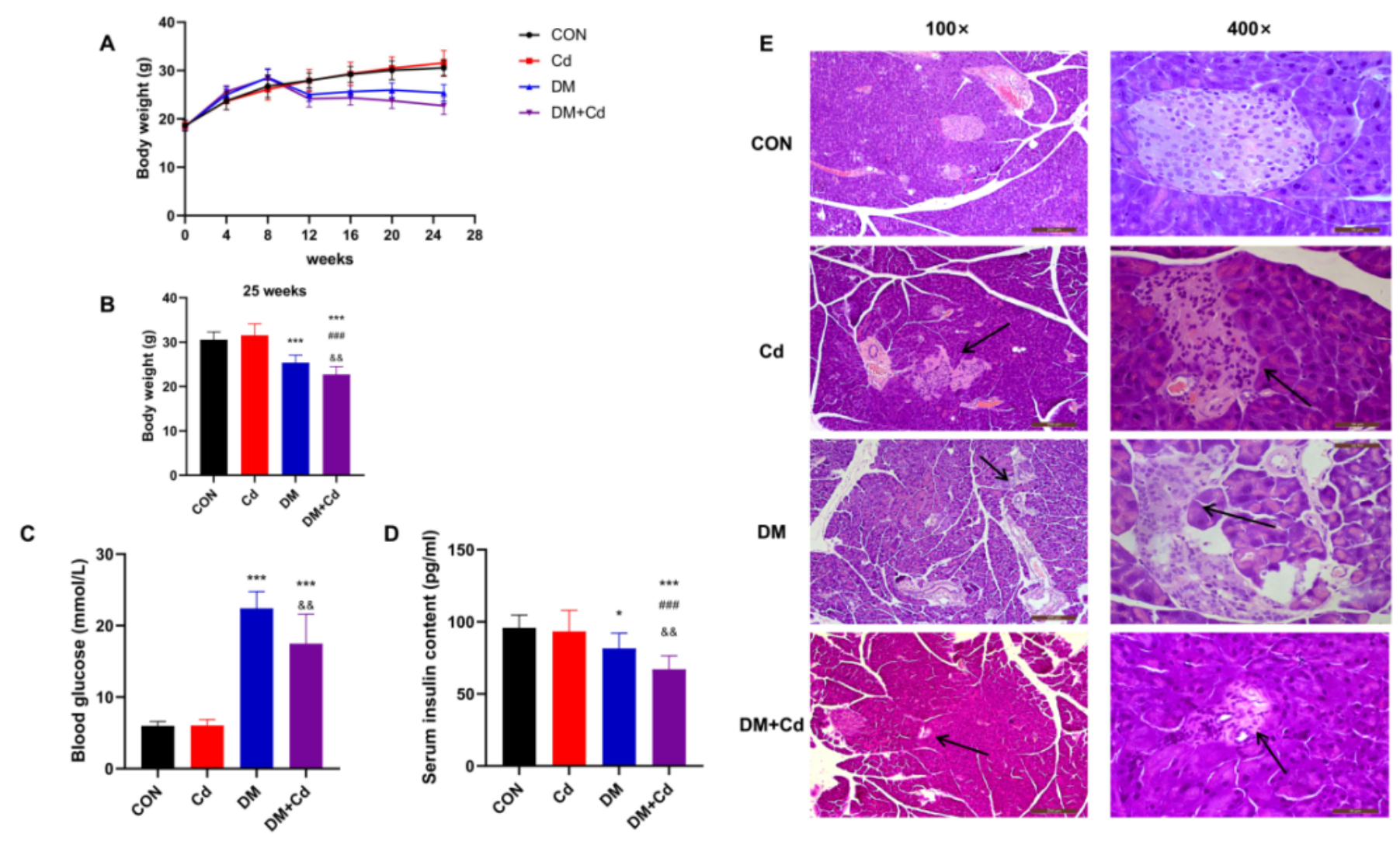

Figure 1

Cd decreased fasting blood glucose and serum insulin concentrations in diabetic mice. (A) The change in body weight of all mice over 25 weeks. (B) Body weight at the 25th week. (C) Fasting blood glucose levels in mice at the 25th week. (D) Serum insulin concentrations in mice at the 25th week. (E) Representative images of pancreas with H\&E staining, the shapes of islets are marked with black arrows. Data are represented as mean $\pm S D$. Statistical significance was considered at ${ }^{\star \star *} P<0.001,{ }^{*} P<0.01,{ }^{*} P<0.05$,

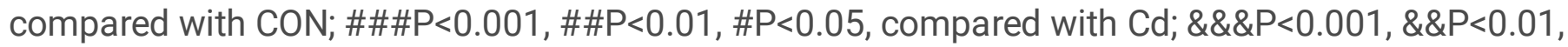
$\& \mathrm{P}<0.05$, compared with $\mathrm{DM}$. 
A

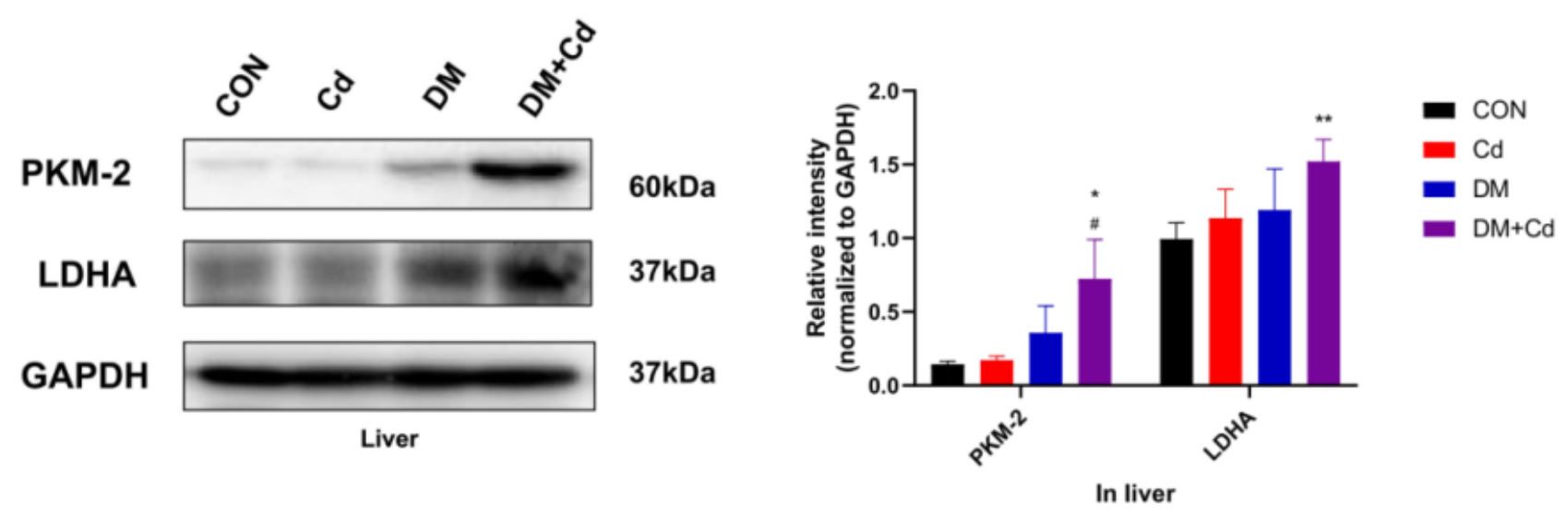

B

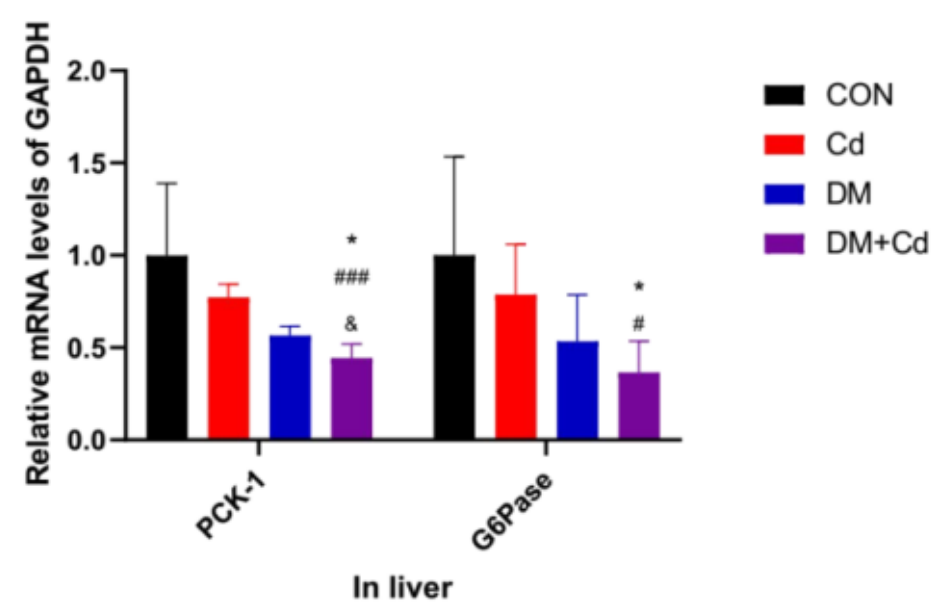

Figure 2

Cd enhanced glycolysis and inhibited gluconeogenesis in diabetic mice. (A) Representative results and densitometric analyses of western blot for PKM-2 and LDHA protein in liver. (B) Relative mRNA levels of PCK-1 and G6Pase in liver. Data are represented as mean \pm SD. Statistical significance is considered at

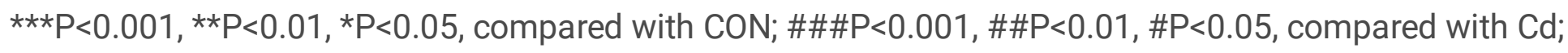
$\& \& \& P<0.001, \& \& P<0.01, \& P<0.05$, compared with $D M$. 
A

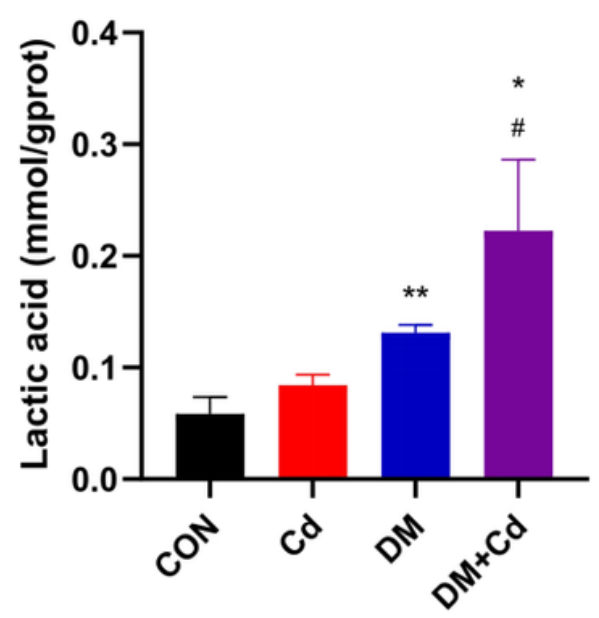

In liver
B

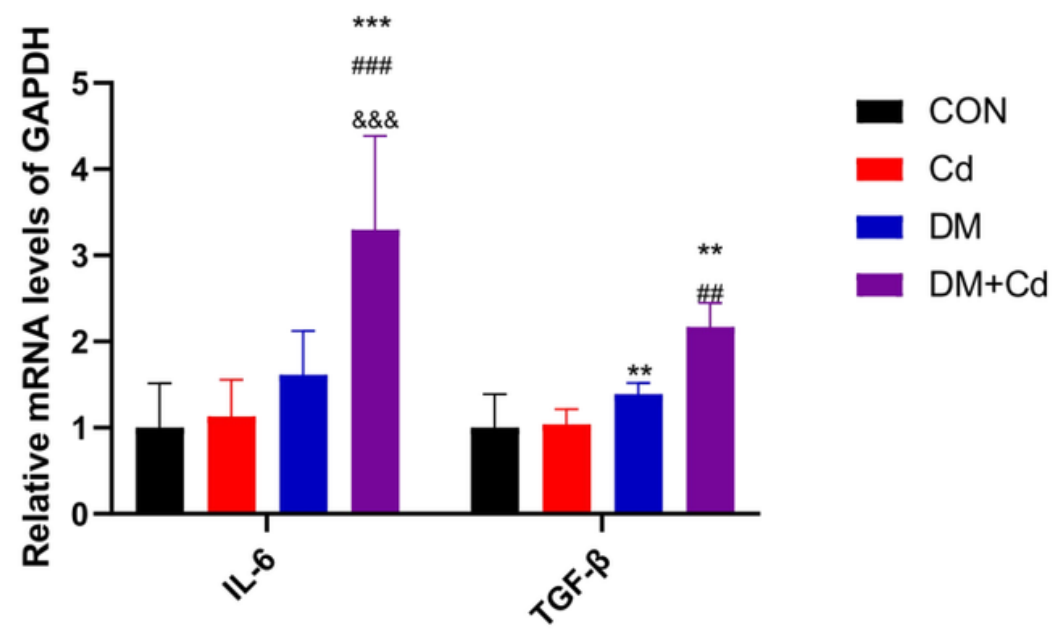

In liver

\section{Figure 3}

Cd increases liver lactate and inflammation levels in diabetic mice. (A) The content of lactate in liver. (B) Relative mRNA levels of IL- 6 and TGF- $\beta$ in liver. Data are represented as mean \pm SD. Statistical significance

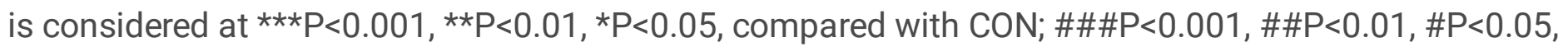
compared with $C d ; \& \& \& P<0.001, \& \& P<0.01, \& P<0.05$, compared with $D M$.

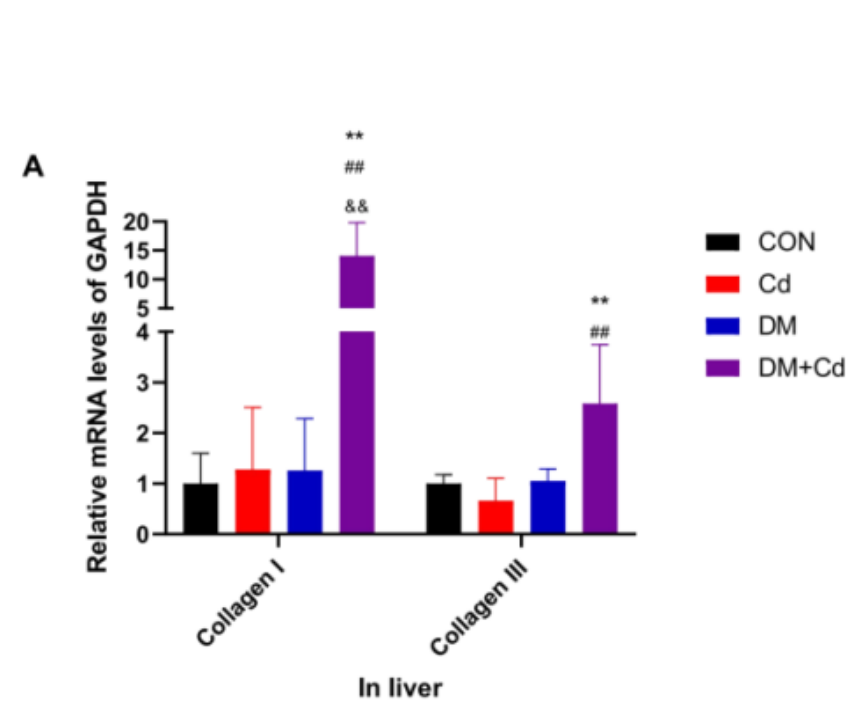

B
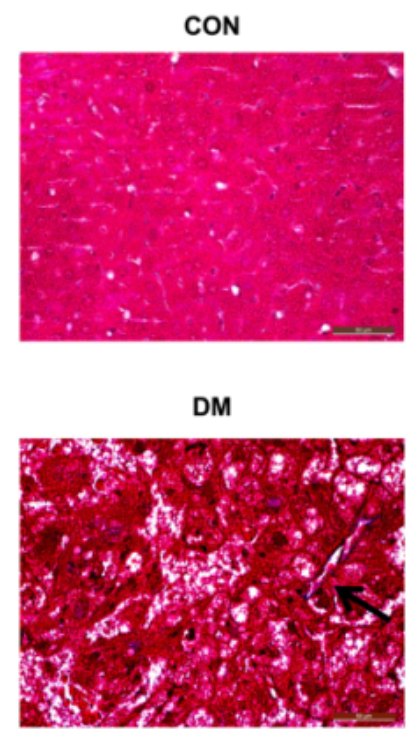

Cd

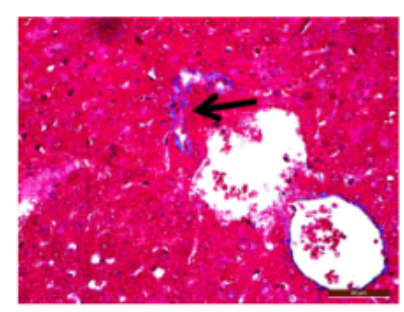

$\mathrm{DM}+\mathrm{Cd}$

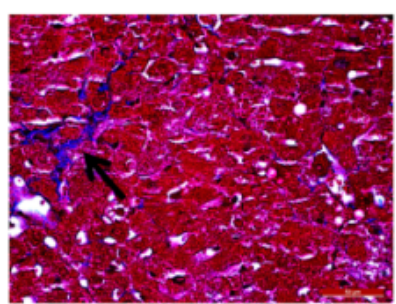

Figure 4

Cd promoted liver fibrosis in diabetic mice. (A) Relative mRNA levels of Collagen I and Collagen III in liver.

(B) Representative images of Masson trichrome staining in liver. Areas of fibrosis indicated with black arrows. Data are represented as mean \pm SD. Statistical significance is considered at $* \star \star * P<0.001, * \star P<0.01$, 


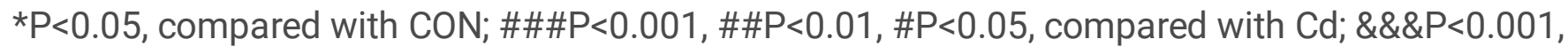
$\& \& P<0.01, \& P<0.05$, compared with $D M$. 